\title{
OFICINA DE PLANTAS MEDICINAIS E DO CERRADO COMO INTERCÂMBIO ENTRE A PESQUISA ACADÊMICA E A PRÁTICA DOCENTE NO ESPAÇO ESCOLAR
}

\section{WORKSHOP ON MEDICINAL AND CERRADO (BRAZILIAN BIOME) PLANTS AS EXCHANGE BETWEEN ACADEMIC RESEARCH AND TEACHING PRACTICE AT SCHOOL}

\author{
Iris de Sousa Lopes ${ }^{1}$, Lucia de Fátima Estevinho Guido ${ }^{2}$, Ana Maria de Oliveira Cunha ${ }^{2}$ e \\ Daniela Franco Carvalho Jacobucci ${ }^{2}$ \\ ${ }^{1}$ Licenciada e Bacharel em Ciências Biológicas pela Universidade Federal de Uberlândia - UFU, \\ irissolo@gmail.com \\ ${ }^{2}$ Universidade Federal de Uberlândia - UFU/Instiuto de Biologia; Programa de Pós-graduação em \\ Educação-FACED/UFU, 38400-902 - Uberlândia - MG - Brasil, luciag@umuarama.ufu.br, \\ anacunha@netsite.com.br, danielafcj@inbio.ufu.br
}

\section{RESUMO}

A Educação Ambiental age como instrumento de conscientização, transformando práticas, ações e atitudes. Atua no sentido de relacionar questões ambientais à realidade vivida pelas pessoas. Valorizar os saberes etnobotânicos tradicionais sobre plantas medicinais acumulados por membros da comunidade, e perpetuá-los, ao unir o conhecimento científico e o popular, amplia as vivências dos membros das comunidades, auxiliando-os nas questões por eles enfrentadas no dia a dia. Professores bem preparados podem fazer uma conexão entre essas temáticas e trabalhar tais questões de modo criativo, interessante e prático para as novas gerações. Esse trabalho investigou as possibilidades de intercâmbio entre projetos de pesquisa acadêmica e prática docente no espaço escolar, através de uma oficina sobre plantas medicinais e do Cerrado. Os resultados mostram que tal atividade é interessante para os alunos, que adquiriram novos conhecimentos, valorizando-os. Para os professores, possibilitou aliar conhecimentos culturais, etnobotânicos e científicos, ampliando-os e incorporando-os na ação docente.

Palavras-chave: Educação Ambiental, Etnobotânica, plantas medicinais, prática docente.

\begin{abstract}
Environmental education acts as an instrument of awareness, changing practices, actions and attitudes. It works towards linking environmental issues to the real experiences of people. Adding value to traditional ethnobotanical knowledge of medicinal plants accumulated by members of the community, and perpetuate them, by uniting the scientific and popular knowledge, widen the experiences of community members and help them on daily issues. Well-prepared teachers can make a connection between these issues and work these issues in a creative, interesting and practical way for the new generations. This study investigated the possibilities of exchange between academic research and teaching practice at school, through a workshop on medicinal and Cerrado (brazilian bioma) plants. The results show that such activity is interesting for students, allows them to acquire new knowledge and to value. For teachers, made it possible to combine cultural knowledge, ethnobotanical and scientific expanding them and incorporating them in the classroom.
\end{abstract}

Keywords: environmental education, ethnobotany, medicinal plants, teaching practice. 


\section{INTRODUÇÃO}

A Educação Ambiental se preocupa com a interação homem-natureza e, nesse aspecto, os estudos etnobotânicos são importantes, pois envolvem a relação entre os conhecimentos ecológicos e biológicos dos vegetais e as sociedades tradicionais (SOBRINHO et al, 2007).

Estudos etnobotânicos têm sido realizados com populações mais diretamente dependentes do ambiente, envolvendo questões relativas ao uso e manejo dos recursos vegetais e as interações das pessoas com as plantas, constatando um profundo conhecimento sobre os organismos e sua ecologia. O saber local está enraizado em contextos culturais e do ambiente e necessita-se de compreender sua lógica, para que seja apreciado e avaliado de forma correta (AMOROZO, 2002).

O conhecimento popular sobre plantas medicinais é muito diversificado e para algumas populações de países em desenvolvimento, esta é a única alternativa para tratamentos de saúde (SANTOS et al, 2008).

Vários trabalhos etnobiológicos têm sido realizados nos últimos anos e a Etnobotânica é um dos campos mais desenvolvidos. Seus estudos incluem o valor dos recursos biológicos focados nos aspectos medicinais presentes em várias culturas e etnias (ALMEIDA e ALBUQUERQUE, 2002).

A Educação Ambiental pode ser uma maneira interessante de realizar um intercâmbio com a Etnobiologia, no intuito de resgatar o conhecimento popular, envolver as populações, promover a valorização dos saberes culturais por respeitar o modo de vida da população local (SOBRINHO et al, 2007).

O conhecimento local tem se mostrado valioso através dos tempos e os povos autóctones detêm uma grande quantidade de informação inexplorada pela ciência oficial (AMOROZO, 2002).

Santos et al (2008), afirmam que os estudos etnobotânicos propiciam conhecimentos a respeito da relação homem-natureza, fornecem subsídios para registrar informações valiosas provenientes de ancestrais e contribuem para o progresso dos estudos fitoquímicos e farmacológicos, sendo estes subsidiados pelas matérias-prima que são fornecidas pelos informantes aos pesquisadores das áreas afins para as devidas análises.

A composição de uma farmacopéia popular é um processo dinâmico que pode crescer quando a comunidade tem contato com migrantes e novas plantas e seus usos ou 
novos usos para as plantas já existentes. Ou pode sofrer perdas de espécies e conhecimentos sobre elas devido a alterações antrópicas que afetam ambientes locais onde estas plantas crescem (AMOROZO, 2002). Albuquerque e Andrade (2002), afirmam que a perda cultural e mudanças sociais geram problemas irreversíveis e diminuem as chances de se promover o desenvolvimento sustentável baseado nas experiências locais.

O potencial de uso das plantas medicinais do Cerrado exige pesquisas que promovam práticas de preservação deste rico bioma ainda pouco estudado. Torna-se necessário investir na divulgação e valorização do conhecimento prático das comunidades com ações educativas voltadas especialmente para os jovens oriundos delas, proporcionando assim a união dos conhecimentos científicos e culturais (BARBOSA, 2004).

Amorozo (2002) defende o investimento em pesquisas que resgatem o conhecimento popular, para que este possa ser registrado e informado a novas gerações. A Universidade e instituições de pesquisa têm uma grande responsabilidade em resgatar, promover e perpetuar experiências vivenciadas por comunidades tradicionais.

Dessa forma, fica evidente a indispensável conexão entre Educação Ambiental e o conhecimento etnobotânico de domínio da população. Em virtude das necessidades urgentes de mobilização das pessoas para as questões ambientais e como meio de resgatar, conhecer e valorizar o conhecimento popular, o presente estudo teve como objetivo principal investigar como a formação continuada de professores, por meio de um grupo de estudos coletivos em Educação Ambiental, contribui para o desenvolvimento de ações práticas de resgate cultural e etnobotânico sobre plantas medicinais e do Cerrado, com a comunidade e alunos da escola básica.

\section{DELINEAMENTO METODOLÓGICO DA PESQUISA}

Este trabalho se constitui como uma pesquisa qualitativa (LUDKE; ANDRÉ, 1986; LAVILLE; DIONNE, 1999) do tipo estudo de caso, definida por Megid Neto (2001) como um estudo que focaliza indivíduos ou organizações educacionais, utilizando preferencialmente técnicas e métodos característicos da abordagem qualitativa, e que considera um grande número de dimensões e variáveis a serem observadas e interrelacionadas, para a descrição de uma realidade ampla.

A pesquisa foi desenvolvida tendo como objeto de investigação o grupo temático de Educação Ambiental associado ao projeto “O potencial de uma proposta coletiva para o 
ensino de Biologia, na transformação da prática docente dos professores de Ciências do Ensino Fundamental", financiado pela Fundação de Amparo à Pesquisa do Estado de Minas Gerais (FAPEMIG) e desenvolvido no formato de parceria entre a Universidade Federal de Uberlândia e a Secretaria Municipal de Educação de Uberlândia - MG.

Dentre as várias atividades de estudo e intervenção realizadas pelo Grupo de Educação Ambiental, foi desenvolvida a oficina "Conhecendo mais sobre plantas medicinais", para a investigação do potencial dessa proposta como metodologia de ensino. Esta oficina foi realizada na Escola Municipal Sebastião Rangel, pertencente ao distrito de Tapuirama em Uberlândia - MG.

A coleta de dados envolveu o acompanhamento das discussões realizadas no grupo temático de Educação Ambiental através de registro em caderno de campo, análise de imagens fotográficas e de filmagem da oficina sobre plantas medicinais e do Cerrado, entrevista gravada em áudio com a professora da Educação Básica responsável pela oficina e expressões dos alunos em textos produzidos sobre a oficina.

\section{O GRUPO DE EDUCAÇÃO AMBIENTAL}

Os professores envolvidos no Grupo de Educação Ambiental são do Ensino Fundamental, de escolas públicas, tanto estaduais quanto municipais de Uberlândia MG. Além dos professores da Educação Básica, integram o grupo, professorespesquisadores da Universidade Federal de Uberlândia, tanto de áreas específicas das Ciências Biológicas (Ecologia, Biologia Animal, Biologia Vegetal, Biologia celular e corpo humano e Genética) como do Núcleo Pedagógico, e licenciandos em Ciências Biológicas.

A proposta envolveu inicialmente reuniões quinzenais, de aproximadamente quatro horas de duração, para aprofundamento teórico na área da Educação Ambiental e planejamento de atividades de intervenção junto aos alunos das escolas nas quais esses professores lecionam. No ano de 2008, a maioria das reuniões foi realizada no Laboratório de Ensino de Ciências e Biologia (LEN) do Instituto de Biologia da Universidade Federal de Uberlândia e, em 2009, os encontros passaram a ser realizados no Centro Municipal de Estudos e Pesquisas (CEMEPE), um espaço destinado à formação continuada de professores da rede municipal de ensino.

Os graves problemas ambientais, sociais e econômicos enfrentados pela sociedade moderna exigem uma atualização por parte do profissional da educação, haja vista sua 
grande responsabilidade como educador, formador de opinião e referencial para os mais jovens.

Forteza e Diniz (2004) priorizam o grupo de estudo com participação voluntária dos professores com o objetivo de diminuir a alienação, refletir criticamente sobre o trabalho realizado e seus objetivos, valorizar o papel social do educador e da escola, promover estudos teóricos e aliá-los à prática.

A temática ambiental engloba todos estes fatores, pois o desenvolvimento econômico e social, bem como a qualidade de vida de todos os seres, estão intrinsecamente ligados ao meio ambiente ou dele dependem.

Para Barreiro (2004), o trabalho docente vai além da sala de aula e é afetado por fatores externos como a realidade social e seus contextos.

Guimarães e Vasconcelos (2006) afirmam que vivemos hoje uma séria crise ambiental e os problemas socioambientais são questões centrais para a compreensão do mundo contemporâneo relacionada à civilidade e seus paradigmas. Nesse ambiente de crise, a Educação desempenha função social que contribui na construção da sustentabilidade socioambiental, propiciando à população que essa seja cientificamente alfabetizada e politicamente consciente e engajada, ampliando o exercício da cidadania. Somente com esta base o cidadão poderá envolver-se no enfrentamento das questões socioambientais. Além disso, faz-se necessário o engajamento entre ciência e cultura para a construção de um modelo de sociedade ecológica e socialmente sustentável.

Tornar o ensino real, útil, prático e significativo para os alunos motivando-os ao aprendizado e à interação são nobres objetivos a serem alcançados pelo docente. Esses só serão plausíveis com esforço contínuo do docente que se empenha em sanar as falhas da sua formação inicial e investe numa formação continuada de qualidade, se tornando um professor reflexivo. Nesse sentido os grupos de estudos coletivos se constituem em oportunidades ímpares, pois os professores têm espaço e voz ativa, aprendendo e ensinando suas experiências através da socialização.

Não se pode desconsiderar que a relação da sociedade com a natureza apresenta características peculiares e está mediada por vários fatores históricos que refletem como a sociedade se organiza visando à produção. A partir dos anos 1960 tem havido avanços em relação às práticas sociais. Existe forte tendência em se apresentar o meio natural em uma perspectiva descritiva e classificatória, dificultando assim que se tenha uma visão mais geral e uma compreensão de conjunto. Enfatiza-se a necessidade de trabalhar os diferentes conhecimentos científicos e os processos de produção de tal conhecimento 
relacionando-os aos mundos naturais, culturais e de produções artísticas, desmistificando-os. Necessita-se torná-los úteis e práticos, relacionando-os às aplicações da Ciência e não se ater a conceitos sem significados para os alunos (CARVALHO, 2005).

A oportunidade de colocar em prática novas metodologias e elaborar uma aula diferente do convencional quadro e giz, foi viabilizada pela integração de professores no grupo de estudos coletivos de Educação Ambiental, o que possibilitou o contato com os projetos de pesquisa desenvolvidos pelos professores da Universidade, nas áreas de Educação Ambiental e Etnobotânica, realizando atualização de conteúdos nessas temáticas e utilização do espaço escolar para o desenvolvimento de novas práticas pedagógicas.

\section{INTERCÂMBIO DOCENTE: UNIVERSIDADE-ESCOLA BÁSICA}

As primeiras atividades do Grupo de Educação Ambiental focaram as pesquisas desenvolvidas pela professora-pesquisadora coordenadora do grupo. A proposta original relacionava-se ao fato de que o professor universitário poderia colaborar para a formação continuada de professores de Ciências, através da atualização de conteúdos nas temáticas nas quais se especializou e por meio do contato direto com o universo da pesquisa acadêmica, no sentido de desmistificar a figura do cientista e promover um intercâmbio constante entre a educação básica e o ensino superior.

Dessa forma, foram apresentados dois projetos de pesquisa desenvolvidos pelo Grupo de Pesquisa em Etnobiologia, Conservação e Educação Ambiental $^{1}$ da Universidade Federal de Uberlândia. Ambos os projetos se relacionam com as linhas de ações programadas pela Rede Fitocerrado, na região do Triângulo Mineiro, do qual os proponentes do mesmo fazem parte. Esta rede foi criada a partir de uma parceria entre a Universidade Federal de Uberlândia (UFU), Empresa Brasileira de Pesquisa Agropecuária (EMBRAPA), Universidade de Uberaba (UNIUBE), Empresa de Pesquisa Agropecuária de Minas Gerais (EPAMIG) e Universidade Estadual de Minas Gerais (UEMG - Campus Ituiutaba, MG) e outras entidades, adotando metas traçadas pela OMS, que incentiva pesquisas com plantas medicinais. A proposta da rede é organizar a sociedade nos vários segmentos em torno dos recursos vegetais do Cerrado, resgatando a cultura popular e com isso preservar a biodiversidade. Para alcançar esse

\footnotetext{
${ }^{1}$ http://grupoetno.blogspot.com/
} 
objetivo, torna-se importante investir também na Educação Ambiental da população como um todo, especialmente as crianças. A pesquisa da Rede Fitocerrado será realizada a partir do conhecimento que as populações investigadas possuem sobre os usos das plantas do Cerrado nas suas diversas atividades cotidianas.

Um dos projetos, intitulado "Levantamento dos usos de plantas do Bioma Cerrado no município de Uberlândia, $\mathrm{MG}^{\prime \prime}$, tem como objetivo geral levantar qualitativa e quantitativamente as espécies vegetais do Cerrado com potencial medicinal e outros valores agregados (fontes de fibras, alimentos, cultos religiosos, corante têxtil, benzeção, ornamental, artesanal e outros) utilizadas pela população de quatro distritos do município de Uberlândia, MG.

O outro projeto, "Educação Ambiental a partir do resgate dos quintais e seu valor etnobotânico em distritos rurais do Município de Uberlândia, $\mathrm{MG}^{\text {”3, }}$, tem como objetivo geral realizar a caracterização dos quintais de alguns grupos familiares residentes nos distritos rurais do município de Uberlândia do ponto de vista etnobotânico, visando gerar informações capazes de dar visibilidade às atividades de Educação Ambiental. Ao conhecer como as pessoas se relacionam com as plantas no seu cotidiano é possível resgatar e valorizar o conhecimento dessa população, as práticas de manejo por elas utilizadas e assim contribuir para uma Educação Ambiental sustentada pela troca de conhecimentos.

Os trabalhos desenvolvidos foram apresentados aos professores membros do grupo de estudos coletivos no qual havia duas professoras dos distritos participando. Surgiu assim um intercâmbio e uma conexão entre as atividades desenvolvidas no grupo de estudos coletivos e as realizadas nos projetos. As professoras do grupo de Educação Ambiental puderam ampliar seus conhecimentos e estender as informações aos alunos por meio de ações práticas, com participação da comunidade.

A professora da Educação Básica, responsável pelas aulas na escola do distrito comentou sobre a importância da parceria com os pesquisadores da Universidade para a realização da oficina de plantas medicinais e do Cerrado e afirmou que "se não houvesse o intercâmbio com os professores da UFU e o grupo de estudos coletivos, essa oportunidade não existiria” .

Megid Neto e colaboradores (2007) afirmam que a Universidade não tem conseguido transferir o conhecimento produzido sobre formação de professores para as

\footnotetext{
${ }^{2}$ Financiado pela Fundação de Amparo à Pesquisa de Minas Gerais (FAPEMIG) .

${ }^{3}$ Financiado pela Pró-reitoria de Pesquisa e Pós-Graduação da Universidade Federal de Uberlândia.
} 
atividades práticas, existindo uma lacuna e falta de integração da Universidade com a Educação Básica. Os pesquisadores pensam e criam novos projetos, mas os consumidores destes vivem outra realidade e se vêem apartados dos processos de criação destas metodologias inovadoras. Aí existe uma relação de exterioridade e os cursos de formação ficam como teóricos e não resultado da prática docente. Estes cursos deveriam partir da vivência do professor e sua realidade escolar.

Auth (2007) afirma que é necessário envolver os professores da Universidade com os da escola básica, formar parceria para desenvolver a formação continuada e formação inicial. Ele verificou que embora houvesse resistência inicial por parte de vários professores da escola básica, a persistência e desenvolvimento de projetos em parceria, além do envolvimento dos alunos e os resultados obtidos motivaram a continuidade dos trabalhos.

Ficou evidente a importância da participação da professora-pesquisadora da Universidade como coordenadora do Grupo de Educação Ambiental para promover debates aprofundados sobre a temática e estimular os professores da educação básica a realizarem atividades inovadoras para abordar conteúdos relacionados à preservação do meio ambiente.

\section{OFICINA DE PLANTAS MEDICINAIS}

As atividades do projeto de resgate dos quintais nos distritos de Uberlândia já vinham sendo realizadas pela professora-coordenadora do grupo e alunos da graduação. Por coordenar o grupo de estudos coletivos na temática de Educação Ambiental, tornou conhecido aos membros do grupo as atividades em andamento nos distritos. Foi proposta a uma das professoras que leciona na escola do distrito de Tapuirama, e faz parte do grupo de estudos coletivos, a realização da oficina de plantas medicinais, como extensão do trabalho de resgate cultural já iniciado.

Em fevereiro de 2009, foi realizada a oficina de plantas medicinais com o tema "Conhecendo mais sobre plantas medicinais". A atividade foi proposta e organizada de forma integrada pela professora-pesquisadora, alunos da graduação em Ciências Biológicas e duas senhoras da comunidade conhecedoras de plantas medicinais e seus usos, além da colaboração da professora da escola do distrito. A proposta inicial da oficina foi socializar os resultados de trabalhos de pesquisa nos distritos de Uberlândia e enfatizar a importância das plantas medicinais e dos quintais. 
Antes da realização da oficina, foi elaborada uma sondagem com os alunos, através de questionário, para investigar o conhecimento prévio destes sobre as plantas e sua utilidade. Todas as espécies utilizadas na oficina foram coletadas nos quintais do distrito de Tapuirama. Os 40 alunos participantes eram do $8^{\circ}$ ano da escola municipal do distrito.

A realização da oficina incluiu a análise das características das plantas medicinais, aromáticas e do Cerrado, e posterior identificação das espécies usando chaves de identificação simplificadas.

Os alunos foram divididos em oito grupos e metade deles ficou na sala de aula e a outra metade no laboratório de Ciências. Cada grupo deveria fazer a observação das espécies amostradas e anotar as principais características observadas, como: tipo de folha, odor, nome popular, característica mais chamativa, e para que serve tal planta. As moradoras locais explicaram detalhadamente cada planta, enfatizando seus usos, preparos e suas próprias experiências com seus quintais.

Após as anotações dos detalhes observados e as explicações das moradoras, os graduandos da UFU e os professores explicaram sobre os nomes científicos das plantas, e a importância de conhecer e identificar de forma correta as espécies vegetais.

A execução da atividade na escola possibilitou a integração das senhoras da comunidade com o ambiente escolar, oportunizando a transmissão de suas experiências e conhecimentos sobre o uso de plantas medicinais e seus quintais. Esse intercâmbio serviu para incentivar os alunos a aumentar o interesse em conhecer mais sobre plantas e valorizar seus quintais e o conhecimento oriundo de pessoas mais experientes como avós, pais, mães, tios e outros membros da comunidade.

A escola pode funcionar como um instrumento no resgate do conhecimento sobre plantas do Cerrado que em muitos casos tem se perdido ao longo das gerações e não tem suscitado interesse nos mais jovens em aprender e transmitir a outros, agindo como multiplicadores como seus antepassados.

\section{AVALIAÇÃO DA OFICINA PELAS EXPRESSÕES DOS ALUNOS}

A última etapa da oficina envolveu a expressão dos alunos através de um texto que foram incentivados a produzir descrevendo suas percepções sobre a atividade, por meio dos seguintes quesitos: o interesse suscitado, a importância e conhecimentos adquiridos.

Vinte e nove alunos produziram textos revelando suas percepções sobre a atividade. A análise dos mesmos revelou alto grau de satisfação em aprender sobre o tema. A 
respeito do interesse dos alunos, as expressões mais comuns foram: "eu amei essa aula"; "gostei muito da aula, eu aprendi coisas que eu nunca imaginei"; "eu adorei a oficina sobre plantas medicinais, pois ensina-nos sobre o que nem a minha mãe sabia; foi muito interessante, pois algumas plantas eu nem sonhava que poderia existir..."; "eu gostei mesmo dessa palestra; eu não sabia muito que as plantas tinham essas coisas... gostei mesmo, eles estão de parabéns porque foi uma palestra ótima, muito legal e eu adorei”.

Faltou uma denominação específica e unânime por parte dos alunos a respeito deste evento, pois alguns se referiram a ele como oficina, palestra ou aula. Isto talvez reflita a falta de uma proposta mais contundente da equipe proponente da atividade, a professora universitária e seus alunos, a professora da escola e as moradoras locais. Porém, ficou evidente que para os alunos foi diferente da tradicional aula quadro-giz, a ponto de não saberem denominá-la apropriadamente.

Certamente, o modo como esse conhecimento foi trabalhado contribuiu para aguçar o interesse dos alunos, visto que eles puderam interagir, questionar, manusear as plantas, tocar, cheirar e sentir. Isto fica evidente no texto que um aluno produziu: “Aprendemos sobre os remédios que essas plantas produzem, demos nossas opiniões, fizemos perguntas e fizemos algumas atividades sobre essas plantas." Visualizar os detalhes e apalpar favorece o aprendizado, conforme manifesto por outro aluno: "Algumas plantas que não conhecemos e seus nomes científicos e suas características de suas folhas e galhos ajudam na identificação de algumas plantas que são encontradas e não sabemos o nome".

A oficina permitiu conciliar um tema complexo como Educação Ambiental, com a realidade vivida pelos alunos, em seu contexto social, ajudando-os a conhecer as plantas de seu próprio quintal, a valorizá-las e preservá-las. Sobre isso, outro aluno escreveu: "Eu gostei muito da aula que tivemos sobre plantas medicinais por que assim eu aprendi para que servem as plantas que temos, as plantas do nosso quintal...". Outro aluno mencionou: "Na minha opinião deveria ter mais aulas sobre plantas medicinais e aromáticas, porque é sempre bom se conhecer várias plantas. A aula sobre plantas foi tão importante que eu aprendi o nome de uma planta que tem aqui em casa que é o capim cidreira.” E outro disse: “...as mulheres que ensinaram nós (sic) os nomes das plantas medicinais que tem no quintal de nossa casa...eu aprendi muitas coisas...por isso é muito importante estudar ciências em nossa vida”. O desejo de aprender mais ficou evidente na seguinte expressão: "Eu gostaria de ter outra aula como aquela pra poder 
aprender mais, porque eles nos mostraram a serventia para outras plantas que tem em meu quintal...".

A respeito da importância desse conhecimento para a vida, nove alunos consideraram "importante" ou "muito importante"; outros consideraram "úteis" ou "muito úteis". Um aluno escreveu: "Essa palestra foi muito importante para nós, pois serviu para conhecermos um pouco mais sobre as plantas, conhecer para que cada planta serve, e assim quando precisarmos de algum remédio para alguma coisa, usarmos a planta certa para aquilo." Outro se manifestou dizendo: "As ervas são encontradas na natureza em grandes variedades. Com vastas possibilidades de utilização, elas são muito úteis na culinária, no uso medicinal e também em outros campos".

O valor deste conhecimento é evidente também no sentido de diferenciar os remédios dos venenos ou plantas tóxicas, conforme mencionou um aluno “... eu acho que as plantas fazem parte da vida das pessoas, e as plantas podem salvar as vidas de muitas pessoas e também tem plantas que podem matar ou fazer as pessoas passarem mal; é bom ficar sabendo sobre as plantas".

Os conhecimentos etnobotânicos são a base para ações interdisciplinares e fomento de pesquisas por parte de químicos, médicos, botânicos e agrônomos com o objetivo da produção de novos medicamentos, o que justifica seus usos e conservação. Alguns alunos enxergaram esta perspectiva e se expressaram a respeito, pontuando: "Por isso acho que é importante estudos de remédios caseiros através de plantas medicinais e aromáticas, que podem futuramente auxiliar toda a medicina. Todos devem conhecer as plantas medicinais e estudá-las profundamente”. Sobre a importância da conservação outro aluno escreveu: "Essa aula sobre plantas me ensinou muitas coisas legais e interessantes, vamos preservar mais as plantas que temos nos quintais, porque talvez a planta que você arranca talvez irá curar uma doença sua, de seu vizinho, etc".

A professora de Educação Básica, da escola do distrito disse: "a gente foi para a escola para descobrir o que é que os alunos sabem sobre plantas medicinais, porque as pessoas entrevistadas são os avós e os tios de alguns deles. Promover esse resgate da cultura, que uso eles fazem dessas plantas, se eles conhecem”. E os alunos puderam externar seus conhecimentos colocando-os por escrito, facilitando assim a percepção dos resultados obtidos.

Embora não tenha sido possível verificar até que ponto tais conhecimentos produzirão ações concretas nos envolvidos, pois a mudança nas atitudes não é uma tarefa fácil para professores ensinarem, assim como conseguirem verificar se seus 
ensinos realmente provocaram as mudanças esperadas, o desafio de fazer algo diferente e investir na formação continuada produz um senso de segurança no docente e motivação para experimentar novas metodologias. (TRIVELATO, 2001).

Neste sentido, Souza e Gouvêa (2006) defendem que a atualização profissional deve ser permanente para tornar o educador seguro e competente, vencendo as limitações da formação inicial.

\section{INTEGRANDO EDUCAÇÃO AMBIENTAL E ETNOBOTÂNICA}

Sobrinho et al ( 2007), afirma que a Educação Ambiental se preocupa com a relação homem-natureza e um dos aspectos dos estudos etnobotânicos é conciliar proteção dos ecossistemas com o manejo adequado dos recursos naturais. Assim, a Etnobiologia deve se articular à Educação Ambiental no intuito de promover uma troca de saberes entre os informantes da comunidade e os pesquisadores.

Amorozo (2002) propõe que embora a Ciência e saber local sejam sistemas de conhecimento com ênfases e abordagens diferentes, porém, se trabalhados em conjunto, trariam resultados mais produtivos ao se lidar com as questões relacionadas ao uso e conservação de recursos biológicos.

Devido à enorme riqueza da diversidade vegetal no Brasil, assim como o vasto conhecimento étnico-cultural, o uso popular de plantas medicinais é muito relevante e os estudos etnobotânicos são importantes, pois possibilitam o resgate e perpetuação dos conhecimentos populares das comunidades (SANTOS et al, 2008).

A realização da oficina de plantas medicinais propôs trabalhar a Etnobotânica e a Educação Ambiental numa perspectiva de valorização do conhecimento popular aliado ao científico. Partindo de suas vivências, ao usar as plantas que os alunos possuem em seus quintais, ampliou-se o conhecimento favorecendo aprendizagem dos nomes científicos, usos, dosagens e contra-indicações dos remédios caseiros que eles já fazem uso, além de desenvolver uma consciência e ações de conservação do rico bioma Cerrado.

\section{CONSIDERAÇÕES FINAIS}

As informações compartilhadas nesta oficina evidenciam que a escola possui um papel central na promoção e divulgação do conhecimento etnobotânico que anteriormente era passado dos mais velhos para os mais jovens, e hoje, em alguns casos, isso tem se perdido. A escola e os professores de todas as disciplinas, não apenas de 
Ciências, podem valorizar o conhecimento popular regional, através de parcerias com a comunidade, a fim de que este saber tão rico não se perca, mas que possa ser perpetuado.

O dever do educador inclui situar o aluno no meio em que ele vive, instigando-o a ampliar seus conhecimentos sobre o Cerrado e a sua biodiversidade. Uma fonte rica de informações e pesquisa está muito próxima de todos eles, seus quintais, especialmente neste caso, um distrito, em que a maioria das pessoas vive como uma comunidade, as casas têm quintais e plantas diversas, e há troca de saberes, pois quase todos os moradores se conhecem. Os alunos ficaram orgulhosos de ver seus conhecidos e parentes participando da oficina, ensinando na escola deles.

Alcançou-se o objetivo pretendido que incluía descobrir o que os alunos sabem sobre plantas medicinais e do Cerrado, seus usos e importância da preservação, promover um resgate cultural desta temática e avaliar o que tem sido repassado para as gerações mais jovens.

Percebe-se que os alunos reconheceram a atividade como interessante, importante, e adquiriram vários conhecimentos sobre as plantas medicinais e do Cerrado. Não foi possível avaliar até que ponto o conhecimento agiu como instrumento para motivar à ação prática, efetiva, no sentido de conservação das plantas dos quintais. Seria interessante, em trabalhos futuros, verificar o que de fato mudou na atitude e ações dos jovens após obtenção das valiosas informações veiculadas na oficina, no seu dia a dia, e o que têm feito para mostrar que as plantas possuem mesmo a importância que descreveram.

Em relação à formação continuada de professores, a pesquisa desenvolvida revela que de forma integrada, a oficina possibilitou o intercâmbio de conhecimentos entre os projetos de pesquisa gestados no universo acadêmico e o conhecimento popular sobre plantas medicinais e do Cerrado, que somente foi viável com a parceria entre os professores-pesquisadores e a professora da educação básica.

\section{REFERÊNCIAS BIBLIOGRÁFICAS}

ALBUQUERQUE, U.P. de; ANDRADE, L. de H. C.Uso de recursos vegetais da Caatinga: o caso do Agreste do Estado de Pernambuco (Nordeste do Brasil).

Interciência, v.27, n.7, p. 1-13, 2002. 
ALMEIDA, C. de F. C. B. R. de; ALBUQUERQUE, U. P. de. Uso e conservação de plantas e animais medicinais no Estado de Pernambuco (Nordeste do Brasil): um estudo de caso. Interciência, v. 27, n. 6, p. 276-285, 2002.

AMOROZO, M. C. M. A perspectiva Etnobotânica e a conservação de biodiversidade. In: Congresso da Sociedade Botânica de São Paulo, XIV, 2002, Rio Claro: UNESP, 2002.

AUTH, M.A. Coletivos escolares e interações de professores em formação inicial e continuada. Anais da 30a reunião anual da ANPED. Caxambú, 2007. p.1-12.

BARBOSA, J. M. Análise Etnobotânica de plantas medicinais em comunidades do Município de Uberlândia, MG. Monografia (bacharelado curso de Ciências Biológicas) -Universidade Federal de Uberlândia, Uberlândia, 2004.

BARREIRO, I.M.de F. Novos espaços formativos de professores e prática docente. In: 27ª ANPED, Caxambú /MG. CDROM, 2004. p.1-15.

CARVALHO, L.M.de. A temática ambiental e o ensino de biologia: compreender, valorizar e defender a vida. . MARANDINO, M.; SELLES, S.E.; FERREIRA, M.S.; AMORIN, A.C.(Orgs.). Ensino de Biologia: conhecimentos e valores em disputa. Niterói: Eduff, 2005.

FORTEZA, M.S.; DINIZ, R.E.da S. Grupo de estudo - uma perspectiva de prática crítico-reflexiva na formação continuada de professores. In: NARDI, R.; BASTOS, F.; DINIZ, R.E. da S. (Orgs.). Pesquisas em ensino de ciências: contribuições para a formação de professores. São Paulo: Escrituras, 2004. 254p.

GUIMARÃES, M.; VASCONCELLOS, M. das M.N. Relações entre Educação Ambiental e educação em ciências na complementaridade dos espaços formais e não formais da educação. Educar, n.27, p.147-162, 2006. 
LAVILLE, C.; DIONNE, J. A construção do saber: manual de metodologia da pesquisa em ciências humanas. Porto Alegre: Editora Artes Médicas Sul; Belo Horizonte: Editora UFMG, 1999.

LÜDKE, H.A.L.M.; ANDRÉ, M. Pesquisa em educação: abordagens qualitativas. São Paulo: EPU, 1986.

MEGID NETO, J. Elaboração de Projetos Técnicos de Pesquisa. Campinas: Faculdade de Educação - UNICAMP, 2001.

MEGID NETO, J.; JACOBUCCI, D.F.C.; JACOBUCCI, G.B. Para onde vão os modelos de formação continuada de professores no campo da educação em ciências? Horizontes, v.25, n.1, p.73-85, 2007.

SANTOS, M.R.A. dos; LIMA, M.R. de; FERREIRA, M. das G.R. Uso de plantas medicinais pela população de Ariquemes, em Rondônia. Horticultura Brasileira, v.26, n.2, 2008.

SOBRINHO, I.A.P; GUIDO, L.de F.E.; OLIVEIRA, T.G. de. Jardim de plantas medicinais e aromáticas: a Educação Ambiental valorizando o conhecimento popular. In: Anais do VI ENPEC- Encontro Nacional de Pesquisa em Educação em Ciências ABRAPEC - Florianópolis, 2007. p.01-10.

SOUZA, L.H.P.de.; GOUVÊA, G. Oficinas pedagógicas de ciências: os movimentos pedagógicos predominantes na formação continuada de professores. Ciência \& Educação,v.12, n.3, p.303-313, 2006.

TRIVELATO, S.L.F. O currículo de ciências e a pesquisa em Educação Ambiental. Educação:Teor 